\title{
Polymorphisms of the SCN1A gene in children and adolescents with primary headache and idiopathic or cryptogenic epilepsy: is there a linkage?
}

\author{
Irene Toldo • Alice Bruson - Alberto Casarin - Leonardo Salviati • \\ Clementina Boniver · Stefano Sartori · Pasquale Montagna • \\ Pier Antonio Battistella • Maurizio Clementi
}

Received: 15 March 2011/Accepted: 7 June 2011/Published online: 29 June 2011

(C) The Author(s) 2011. This article is published with open access at Springerlink.com

\begin{abstract}
The purpose of this study was to evaluate the distribution of the polymorphisms of the SCN1A gene in a series of children and adolescents with primary headache and idiopathic or cryptogenic epilepsy compared to controls. Five non-synonymous exonic polymorphisms $(1748 \mathrm{~A}>\mathrm{T}$, 2656T $>\mathrm{C}, \quad 3199 \mathrm{~A}>\mathrm{G}, \quad 5771 \mathrm{G}>\mathrm{A}, \quad 5864 \mathrm{~T}>\mathrm{C})$ of the SCN1A gene were selected and their genotyping was performed, by high resolution melting (HRM), in 49 cases and 100 controls. We found that among the five polymorphisms, only 3199A > G was a true polymorphism. We did not find a statistically significant difference between distribution of 3199A $>\mathrm{G}$ genotypes between cases and controls. We excluded the role of the SCN1A gene in the pathogenesis of comorbidity between headache (especially migraine) and epilepsy. The SCN1A gene is a major gene in different epilepsies and epilepsy syndromes; the HRM could be the new methodology, more rapid and efficacious, for molecular analysis of the SCN1A gene.
\end{abstract}

Keywords Migraine $\cdot$ Epilepsy $\cdot$ Comorbidity $\cdot$ SCN1A gene $\cdot$ Children

P. Montagna: Deceased.

I. Toldo $(\bowtie) \cdot$ C. Boniver · S. Sartori · P. A. Battistella

Child Neurology Unit, Department of Pediatrics,

University of Padua, Via Giustiniani, 3, 35128 Padua, Italy

e-mail: irene.toldo@unipd.it

A. Bruson - A. Casarin - L. Salviati - M. Clementi

Genetic Unit, Department of Pediatrics, University of Padua,

Padua, Italy

P. Montagna

Department of Neurological Sciences,

University of Bologna, Bologna, Italy

\section{Introduction}

Migraine and epilepsy are both common neurological disorders and can occur as comorbid conditions [1-7]. From a genetic point of view, migraine is a polygenic multifactorial disorder [8], while many epilepsy syndromes are monogenic and have been pathogenetically linked to channelopathies [9]. Similarly familial hemiplegic migraine (FHM), the only known autosomal subtype of migraine, is due to mutations in genes encoding ion channels, and it is often associated to epileptic seizures [10]. Previous studies have excluded the role of the two FHM genes (CACN1A, ATP1A2) in the common forms of migraine [8, 11-13].

Considering the multifactorial etiology of migraine, genetic studies on phenotypically homogenous populations are required [8]. The comorbidity between two conditions that share common pathogenetic mechanisms, such as migraine and epilepsy, could address the issue.

The SCN1A gene encodes the $\alpha$-subunit of the neuronal voltage-gated sodium channel $\mathrm{Na}_{\mathrm{v}} 1.1$ (MIM\# 182389). Mutations in SCNIA are associated with a spectrum of epilepsy syndromes [14]; a few mutations result in FHM [15]. So far, SCN1A gene has never been investigated in subjects with common forms of migraine.

The purpose of this study was to evaluate the role of the SCN1A gene in the pathogenesis of comorbidity between primary headache and idiopathic or cryptogenic epilepsy in a large series of children and adolescents.

\section{Materials and methods}

This was a case-control study comparing the genotype distribution and allele frequency of single nucleotide 
polymorphisms (SNPs) of SCN1A gene between patients and healthy controls.

Fifty-six subjects out of 1,795 headache sufferers under the age of 18 consecutively diagnosed at the juvenile Headache Center of the Department of Pediatrics of Padua Hospital between 1995 and 2008 were selected according to the following criteria: (1) primary headache and (2) idiopathic or cryptogenic epilepsy or unprovoked seizures. Patients with secondary headache or symptomatic epilepsy were excluded from the study. The methodology of patients' recruitment and phenotype selection has been previously reported [7]. The study protocol and consent/ assent forms were approved by our Institutional Review Board.

Forty-nine patients and 100 healthy controls participated in the genetic study. All the healthy controls were interviewed by a board certified child neurologist regarding, in particular, the personal history of headache; those affected by migraine or probable migraine, according to the criteria of the International Classification of Headache Disorders (ICHD-II) [16] were excluded.

The molecular analysis was conducted at the Genetic Laboratory of the Department of Pediatrics (University of Padua). Parental informed consent for genetic testing was obtained for each subject included in the study. Genomic DNA was extracted from peripheral blood using the High Pure PCR Template Preparation Kit (Roche Diagnostics GmbH, Mannheim, Germany).

The five SNPs examined are described in Table 1. Primers were designed using the Primer 3 software (http:// frodo.wi.mit.edu/primer3). Primer sequences and amplification conditions for SCN1A gene are available upon request. Genotypes were determined by high resolution melt (HRM) analysis [17-19].

The polymerase chain reaction (PCR) cycling and HRM analysis were carried out sequentially on a Rotor Gene 6000 (Corbett Research, Mortlake, Australia) using Takara Ex Taq R-PCR custom (Takara Bio Europe SAS, Saint-Germain-en-Laye France). The HRM analysis was performed with the temperature ramping $\left(70\right.$ to $95^{\circ} \mathrm{C}$, rising by $0.1^{\circ} \mathrm{C}$ ) and fluorescence acquisition setting recommended by the manufacturer. The melting curves were normalized through calculation of the "line of best fit" of two normalization regions before and after the major fluorescence drop, corresponding to the melting of the PCR product using the software provided with the Rotor Gene 6000 (Corbett Research). Melting profiles and HRM running conditions were determined experimentally in 10 reference controls that were sequenced.

We obtained three different melting profiles only for the 3199A > G polymorphism. We sequenced two samples for each melting profile of each polymorphism, confirming that different profiles corresponded to different sequences. Sequence analysis revealed that heterozygotes and homozygotes have characteristic melting profiles that give rise to differently shaped melting curves. Therefore, in the following HRM analyses we used the curves of homozygotes and heterozygotes that were confirmed by sequencing as the reference for the genotype analysis of the unknown samples.

Direct sequencing of PCR products with abnormal HRM profiles was performed with the use of the BigDye ${ }^{\circledR}$ Terminator v1.1 Cycle Sequencing Kit (Applied Biosystems) on ABI 310 automated DNA sequencer (PE Applied Biosystems, Foster City, CA, USA). The HRM profiles of cases with comorbidity were compared to HRM profiles of healthy reference controls that were sequenced.

The allele frequencies and genotypes in patients and controls were calculated. Genotype distributions in patients and controls were tested for Hardy-Weinberg equilibrium, and differences in genotype frequencies between patients and controls were tested using a Chi-square test for independence, with a level of significance set at 0.05 .

\section{Results}

Among 1,795 headache sufferers under the age of 18 consecutively diagnosed at the juvenile Headache Center of the Department of Pediatrics of Padua Hospital between 1995 and 2008, fifty-six subjects having comorbidity

Table 1 Description of the polymorphisms of the SCN1A gene in this study

\begin{tabular}{|c|c|c|c|c|c|}
\hline Base pair change & Aminoacid & Position & $\begin{array}{l}\text { Frequency of heterozygous } \\
\text { reported in literature }\end{array}$ & Clinical association & Reference \\
\hline c. $1748 \mathrm{~A}>\mathrm{T}$ & p.D583 V & Exon 11 & $\mathrm{ND}$ & NK & NCBI \\
\hline c. $2656 \mathrm{~T}>\mathrm{C}$ & p.S886P & Exon 15 & $\mathrm{ND}$ & NK & NCBI \\
\hline c. $3199 \mathrm{~A}>\mathrm{G}$ & p.T1067A & Exon 16 & 0.33 & $\begin{array}{l}\text { The SNP is more frequent in patients } \\
\text { with epilepsy than in controls ( } 33)\end{array}$ & {$[24,25,27-33]$} \\
\hline c. $5771 \mathrm{G}>\mathrm{A}$ & p.R1924H & Exon 26 & ND & NK & NCBI \\
\hline c. $5864 \mathrm{~T}>\mathrm{C}$ & p.I1955T & Exon 26 & 0.025 & NK & {$[41]$} \\
\hline
\end{tabular}

$N D$ not determined, $N K$ not known 
between primary headache and idiopathic or cryptogenic epilepsy or unprovoked seizures were selected. The clinical characteristics and the statistical analysis of these two population study have been previously reported [7].

The present study focuses on the results of the SCN1A gene molecular analysis, which was undertaken in 49 cases and 100 healthy controls. Among the 49 cases, 45 subjects (92\%) had migraine (M) (38 migraine without aura, 7 migraine with aura) and 4 patients suffered from episodic tension type (ETTH) headache. Considering the type of epilepsy, there were 30 subjects with focal cryptogenic epilepsy (27 M, 3 ETTH), 11 with focal idiopathic epilepsy (10 M, 1 ETTH), and 8 (8 M, 0 ETTH) with idiopathic generalized epilepsy.

The HRM profiles consist of three different graphs (melt temperature, normalized graph and the difference graph) that are visualized all together during the analysis of results. As an example, we report the three graphs concerning the HRM analysis of exon 16 (Fig. 1) and of exon 11 (Fig. 2).

Comparing the HRM profiles of the cases and healthy control samples with those of the sequenced reference controls, we could identify the genotypes of the samples examined.

The polymorphism 3199A $>$ G, having a significant heterozygosity (0.33), exhibited three HRM profiles consistent with the three genotypes (AA, GA, GG), as confirmed by direct sequencing. The other four SNPs having a low or not known heterozygosity disclosed a unique HRM profile, consistent with the wild type genotype.

During HRM analysis of exon 11, we found in one patient a different profile. The PCR product was analyzed by direct sequencing that disclosed a missense variation sequence $1811 \mathrm{G}>\mathrm{A}$ that causes at protein level a replacement of arginine with histidine (R604H). The patient is a 15-year-old boy with a history of childhood absence epilepsy (since 3-6) suffering from episodic tension headache, since the age of 11 . He never experienced febrile seizures or periodic syndromes. The analysis was carried out in both the parents; the mother was negative while the father, who was asymptomatic, carried the missense variation sequence $1811 \mathrm{G}>\mathrm{A}$.

During the analysis of healthy controls, we found in one case a missense variation sequence $5782 \mathrm{C}>\mathrm{G}$ that causes at protein level a replacement of arginine with glycine (R1928G).

The allele and genotype frequencies, respectively, absolute and percentage, of the five SNPs observed in 49 patients and 100 healthy nonmigrainous controls, tested by HRM, are presented in Table 2.

The analysis of the frequency distribution showed that, only for the polymorphism 3199A $>$ G, the two alleles (A: wild type; G: mutated) are represented both in cases and controls; while for the other four SNPs the allele frequency of the wild type was $100 \%$ both in cases and controls, as assessed on a total of 298 alleles, therefore these SNPs are not true polymorphisms in the tested population. In the case of polymorphism 3199A $>$ G, the genotype distributions for the two alleles (A and $G$ ) were in equilibrium under the Hardy-Weinberg law both in cases $(p=0.64)$ and controls $(p=0.44)$ (with Chi-square test the balance is present if $p>0.05$ ). For this polymorphism, the comparison of the distribution of allele $(\mathrm{A}, \mathrm{G})$ and genotype (A/A, $\mathrm{A} / \mathrm{G}, \mathrm{G} / \mathrm{G})$ frequencies in cases and controls by Chi-square test was not statistically significant (respectively, $p=0.49$, $p=0.58)$.
Fig. 1 Rotor Gene 6000 HRM normalized graph of the region amplified for exon 16. SCN1A 3199A > G polymorphism; green, homozygous for the $\mathrm{A}$ allele (AA); red, homozygous for the $\mathrm{G}$ allele $(\mathrm{GG})$; blue, heterozygous (AG)

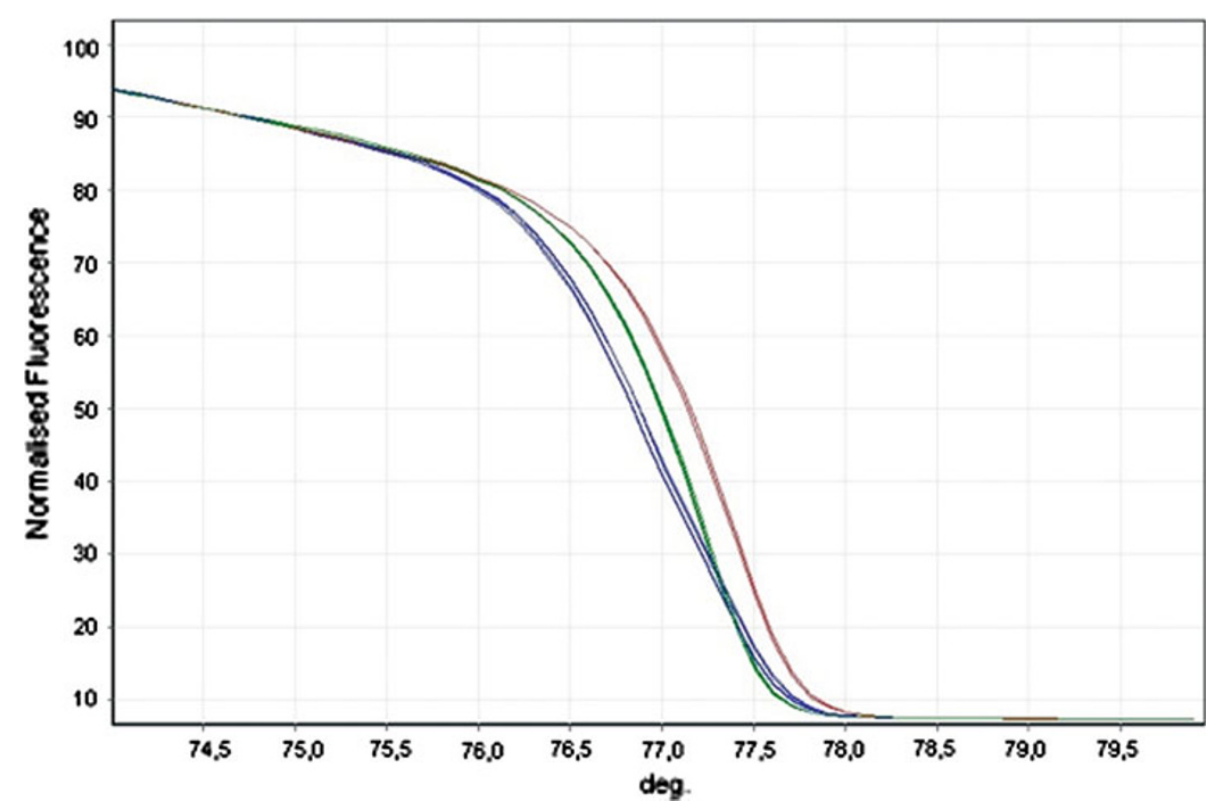


Fig. 2 Rotor Gene 6000 HRM normalized graph of the region amplified for exon 11. SCN1A 1748A $>$ T polymorphism; red (sequenced reference controls), homozygous for the A allele (AA); green (samples examined), homozygous for the A allele (AA)

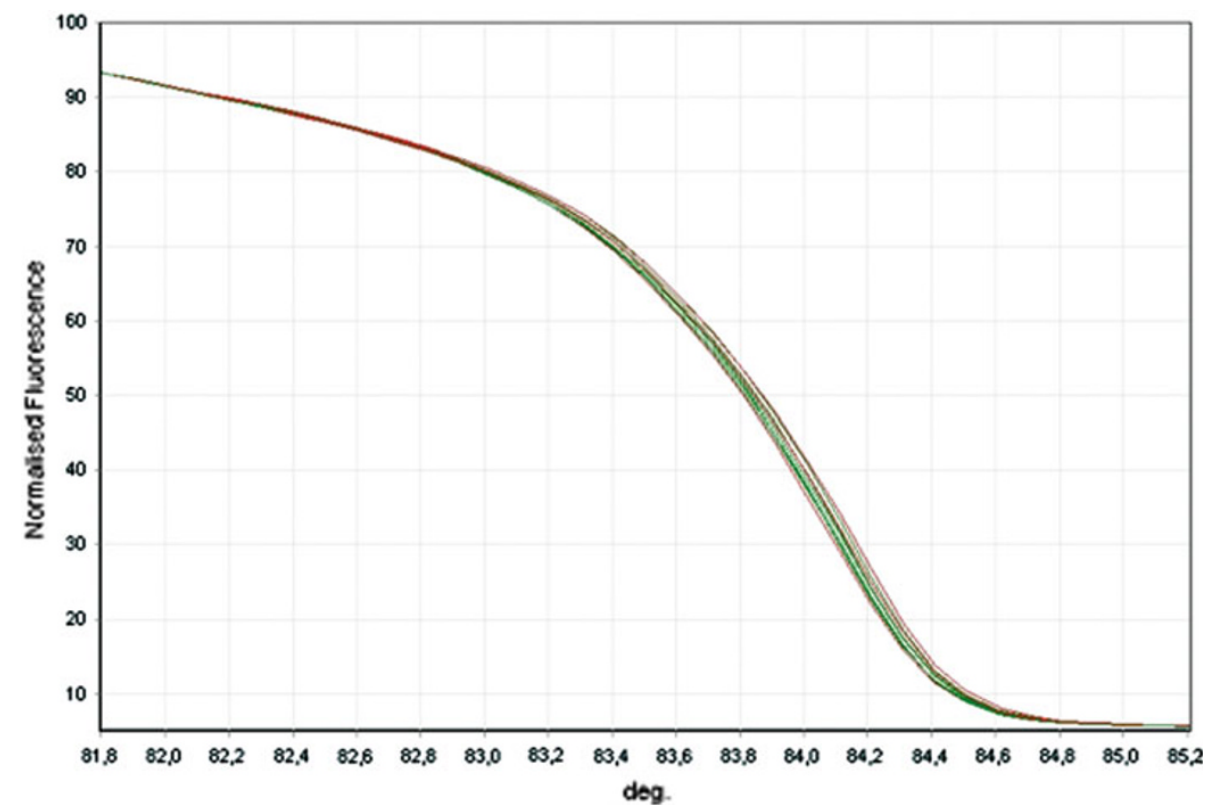

Table 2 Allele and genotype frequencies, respectively absolute and percentage (in brackets), of the five SNPs of the SCN1A gene observed in 49 cases and 100 controls, tested by HRM

\begin{tabular}{|c|c|c|c|c|c|}
\hline & \multicolumn{5}{|c|}{ SNPs of the SCN1A gene } \\
\hline & $1748 \mathrm{~A}>\mathrm{T}$ & $2656 \mathrm{~T}>\mathrm{C}$ & $3199 \mathrm{~A}>\mathrm{G}$ & $5771 \mathrm{G}>\mathrm{A}$ & $5864 \mathrm{~T}>\mathrm{C}$ \\
\hline \multicolumn{6}{|l|}{ Cases $(N=49)$} \\
\hline \multirow[t]{4}{*}{ Allele frequencies } & A & $\mathrm{T}$ & A & G & $\mathrm{T}$ \\
\hline & $98(100 \%)$ & $98(100 \%)$ & $65(66.3 \%)$ & $98(100 \%)$ & $98(100 \%)$ \\
\hline & $\mathrm{T}$ & $\mathrm{C}$ & G & A & $\mathrm{C}$ \\
\hline & $0(0 \%)$ & $0(0 \%)$ & $33(33.7 \%)$ & $0(0 \%)$ & $0(0 \%)$ \\
\hline \multirow[t]{6}{*}{ Genotype frequencies } & $\mathrm{A} / \mathrm{A}$ & $\mathrm{T} / \mathrm{T}$ & $\mathrm{A} / \mathrm{A}$ & $\mathrm{G} / \mathrm{G}$ & $\mathrm{T} / \mathrm{T}$ \\
\hline & $49(100 \%)$ & $49(100 \%)$ & $22(44 \%)$ & $49(100 \%)$ & $49(100 \%)$ \\
\hline & $\mathrm{A} / \mathrm{T}$ & $\mathrm{T} / \mathrm{C}$ & $\mathrm{A} / \mathrm{G}$ & G/A & $\mathrm{T} / \mathrm{C}$ \\
\hline & $0(0 \%)$ & $0(0 \%)$ & $21(44.7 \%)$ & $0(0 \%)$ & $0(0 \%)$ \\
\hline & $\mathrm{T} / \mathrm{T}$ & $\mathrm{C} / \mathrm{C}$ & $\mathrm{G} / \mathrm{G}$ & $\mathrm{A} / \mathrm{A}$ & $\mathrm{C} / \mathrm{C}$ \\
\hline & $0(0 \%)$ & $0(0 \%)$ & $6(11.3 \%)$ & $0(0 \%)$ & $0(0 \%)$ \\
\hline \multicolumn{6}{|l|}{ Controls $(N=100)$} \\
\hline \multirow[t]{4}{*}{ Allele frequencies } & A & $\mathrm{T}$ & A & G & $\mathrm{T}$ \\
\hline & $200(100 \%)$ & $200(100 \%)$ & $123(61.5 \%)$ & $200(100 \%)$ & $200(100 \%)$ \\
\hline & $\mathrm{T}$ & $\mathrm{C}$ & G & A & $\mathrm{C}$ \\
\hline & $0(0 \%)$ & $0(0 \%)$ & $77(38.5 \%)$ & $0(0 \%)$ & $0(0 \%)$ \\
\hline \multirow[t]{6}{*}{ Genotype frequencies } & $\mathrm{A} / \mathrm{A}$ & $\mathrm{T} / \mathrm{T}$ & $\mathrm{A} / \mathrm{A}$ & $\mathrm{G} / \mathrm{G}$ & $\mathrm{T} / \mathrm{T}$ \\
\hline & $100(100 \%)$ & $100(100 \%)$ & $42(37.8 \%)$ & $100(100 \%)$ & $100(100 \%)$ \\
\hline & $\mathrm{A} / \mathrm{T}$ & $\mathrm{T} / \mathrm{C}$ & $\mathrm{A} / \mathrm{G}$ & G/A & $\mathrm{T} / \mathrm{C}$ \\
\hline & $0(0 \%)$ & $0(0 \%)$ & $39(47.4 \%)$ & $0(0 \%)$ & $0(0 \%)$ \\
\hline & $\mathrm{T} / \mathrm{T}$ & $\mathrm{C} / \mathrm{C}$ & $\mathrm{G} / \mathrm{G}$ & $\mathrm{A} / \mathrm{A}$ & $\mathrm{C} / \mathrm{C}$ \\
\hline & $0(0 \%)$ & $0(0 \%)$ & $19(14.8 \%)$ & $0(0 \%)$ & $0(0 \%)$ \\
\hline
\end{tabular}

\section{Discussion}

Previous studies have shown that cases affected by FHM, carrying mutations of genes encoding ion channels
(CACNA1A, ATP1A2, SCN1A), may have seizures [2022].

Molecular analysis of the CACNAIA and ATPIA2 genes in patients with migraine without aura and with aura, has 
shown that these two genes are not involved in common forms of migraine [8, 11-13], although similar studies have not examined the SCNIA gene.

The comorbidity between migraine and epilepsy may allow to select a clinically more homogeneous subgroup of patients in order to carry out genetic studies more targeted than those conducted in patients with common forms of migraine. This is confirmed by the study of Deprez et al. [23], carried out on 20 families with migraine and epilepsy, which showed mutations in the ATP1A2 gene in $10 \%$ of cases, suggesting to perform molecular analysis of this gene in cases where there is comorbidity between migraine and epilepsy and positive family history for migraine or epilepsy.

In our study, molecular analysis of five polymorphisms in coding exons of the SCN1A gene was performed on a large series consisting of 49 subjects with comorbidity between primary headache and idiopathic or cryptogenic epilepsy and 100 healthy nonmigrainous controls.

Among the five SNPs analyzed, only 3199A > G was confirmed to be a polymorphism while the other four SNPs were not true polymorphisms, because they were not found in the 298 alleles (cases and controls) examined and they are not to be further investigated.

We did not find a statistical significant difference of 3199 A > G genotypes' distribution between cases and controls; therefore our results confirm that the polymorphism $3199 \mathrm{~A}>\mathrm{G}$ is not associated to pathological phenotypes in headache sufferers and in migraineurs, similar to that found in other studies conducted on patients with epilepsy.

From a statistical point of view, the group sample sizes achieve a power lower than $20 \%$ to detect, as statistically significant, the observed differences between the two groups for both allele and genotype analyses for the polymorphism 3199A $>$ G. Actually, those differences could be considered negligible from a genetic point of view when bearing in mind the epidemiological and clinical characteristics of the disease. Furthermore, specifically in reference to genotypes, the observed prevalence would suggest that the A/A genotype is less prevalent among wild type subjects, and this would be inconsistent with expected. For these reasons, in our opinion, the results suggest that the observed differences are due to chance.

To our knowledge, this is the first study that has assessed the genotype of polymorphisms in the SCN1A gene in cases with comorbidity between headache and epilepsy.

The SCN1A gene has so far been well studied in large series of patients with severe myoclonic epilepsy [24-26] or in families with idiopathic generalized epilepsies and febrile seizures plus (GEFS+) [27, 28] and also in some families with febrile seizures [29].

These studies also contain data on the frequency of polymorphism 3199A > G of SCN1A gene, and documented genotypic and allelic frequencies comparable between patients and controls. The polymorphism 3199A $>\mathrm{G}$ was analyzed specifically in patients with febrile convulsions [30] or with migrainous vertigo [31] excluding a positive correlation.

In two recent studies, the analysis of polymorphism 3199A $>$ G of the SCN1A gene was conducted in Asiatic patients affected by epilepsy [32, 33]; in both studies genotype distributions in drug-responsive and drug-resistant patients did not differ significantly.

Only in the study of Lakhan et al. [33] a statistically significant correlation between the AG genotype of polymorphism $3199 \mathrm{G}>\mathrm{A}$ and the presence of epilepsy in cases compared to controls has been found; however, this finding deserves further study because the statistical significance was observed only in heterozygous subjects, and thus it is more difficult to explain in terms of biological plausibility. Overall, the results of the studies conducted so far argue that the polymorphism 3199A > G of the SCN1A gene is not associated with pathological phenotypes; our results confirm that this also applies to headache and migraine sufferers.

We found a missense mutation $1811 \mathrm{G}>\mathrm{A}(\mathrm{R} 604 \mathrm{H})$ in exon 11 in a patient with episodic tension headache and childhood epilepsy with absences; in the literature this mutation is already known [34-36]. Escayg et al. [34] identified the same mutation in two patients with juvenile myoclonic epilepsy and emphasized that this mutation interrupts a consensus site for protein kinase $\mathrm{A}$, which is conserved in the four major sodium channel of the central nervous system. However, this mutation did not cosegregate with the epileptic phenotype in two families with juvenile myoclonic epilepsy [34] and had a minor effect on ionic currents in the study by Smith et al. [37]. The possibility that this mutation is not pathogenic has been supported by two subsequent works $[35,36]$. In our case, the pathogenetic significance of this mutation was excluded by carrying out the genetic analysis of the patient's parents; in fact the father was asymptomatic and carried the same sequence variation.

We also confirm that the missense variant $5782 \mathrm{C}>\mathrm{G}$ (R1928G), found in a single healthy nonmigrainous control among the 100 examined, is a rare missense polymorphism, as previously reported [27, 36].

Our study seems to exclude a role of the SCN1A gene in the pathogenesis of migraine and in particular in cases with comorbidity between migraine and epilepsy. The major limitation of the present study is that the genetic analysis has been focused on a part of the gene, since a complete genetic analysis seemed too expensive, given the large number of exons (equal to 26) of the SCN1A gene and based on the negative results in previous studies [27, 38]. 
Our data support the hypothesis [39], that the SCN1A gene is not implicated in the pathogenesis of common forms of migraine, even when the phenotype is restricted by the presence of comorbidity with epilepsy.

The SCN1A gene has a causative role in some epilepsy syndromes (severe myoclonic epilepsy and GEFS+) and has recently been associated with new and different clinical phenotypes, such as focal and generalized cryptogenic epilepsy [35] and atypical Panayiotopoulos syndrome [40].

Another important aspect of this study was the use of an innovative method, the HRM, for the molecular analysis of the SCNIA gene. The HRM offers significant advantages over traditional methods (SSCP, DGGE, DHPLC, etc.), as it does not require manipulation of genetic material after amplification, it is inexpensive, it has excellent sensitivity and specificity and allows the concomitant analysis of a large number of samples, increasing the reproducibility of analysis and significantly reducing the work time.

The sensitivity and specificity of variation detection of HRM are estimated, respectively, to be 100 and 95\% [19].

These characteristics are of particular relevance, especially in the genetic analysis of multifactorial diseases, such as headache and epilepsy, which requires a large number of subjects and very often involves the analysis of several polymorphisms in the same patients. The HRM could then form the new method of molecular analysis of the SCNIA gene, which is currently usually performed with screening techniques (DHPLC) and direct sequencing.

\section{Conclusions}

To the best of our knowledge, this is the first study that evaluated the association between polymorphisms of the SCNIA gene and comorbidity between primary headache (especially migraine) and epilepsy.

Our results confirm that the polymorphism 3199A > G is not associated with pathological phenotypes in patients with headaches and migraine, while the other four polymorphisms examined were homozygous in the tested populations and should not be further investigated.

We exclude the role of the SCNIA gene in the pathogenesis of comorbidity between headache (especially migraine) and epilepsy.

The SCN1A gene is a major gene in different epilepsies and epilepsy syndromes, and in this field it has to be further investigated. The HRM could be a new methodology, more rapid and efficacious, for molecular analysis of the SCN1A gene.

The development of protocols for more efficient and reliable molecular diagnostics would allow a wider appreciation of the role of the SCN1A gene and of other genes encoding for ion channels in different epilepsies and epilepsy syndromes.

Conflict of interest We declare no conflicts of interest.

Open Access This article is distributed under the terms of the Creative Commons Attribution License which permits any use, distribution and reproduction in any medium, provided the original author(s) and source are credited.

\section{References}

1. Haut SR, Bigal ME, Lipton RB (2006) Chronic disorders with episodic manifestations: focus on epilepsy and migraine. Lancet Neurol 5:148-157

2. Andermann E, Andermann FA (1987) Migraine-epilepsy relationships: epidemiological and genetic aspects. In: Andermann F, Lugaresi E (eds) Migraine and epilepsy. Butterworth Publishers, Boston, pp 281-291

3. Andermann F, Zifkin B (1998) The benign occipital lobe epilepsies of childhood: an overview of the idiopathic syndromes and of the relationship to migraine. Epilepsia 39:9-23

4. Andermann F (2000) Migraine and the benign partial epilepsies of childhood: evidence for an association. Epileptic Dis S1:37-39

5. Ottman R, Lipton RB (1994) Comorbidity of migraine and epilepsy. Neurology 44:2105-2110

6. Ottman R, Lipton RB (1996) Is the comorbidity of epilepsy and migraine due to a shared genetic susceptibility? Neurology 47:918-924

7. Toldo I, Perissinotto E, Menegazzo F et al (2010) Comorbidity between headache and epilepsy in a pediatric headache center. J Headache Pain 11:235-240

8. Ducros A, Tournier-Lasserve E, Bousser MG (2002) The genetics of migraine. Lancet Neurol 1:285-293

9. Rees MI (2010) The genetics of epilepsy-the past, the present and future. Seizure 19:680-683

10. de Vries B, Frants RR, Ferrari MD et al (2009) Molecular genetics of migraine. Hum Genet 26:115-132

11. Jen JC, Wan J, Palos TP et al (2005) Mutation in the glutamate transporter EAAT1 causes episodic ataxia, hemiplegia, and seizures. Neurology 65:529-534

12. Kirchmann M, Thomsen LL, Olesen J (2006) The CACNA1A and ATP1A2 genes are not involved in dominantly inherited migraine with aura. Am J Med Genet B Neuropsychiatr Genet 141B:250-256

13. Wessman M, Terwindt GM, Kaunisto MA et al (2007) Migraine: a complex genetic disorder. Lancet Neurol 6:521-532

14. Claes LR, Deprez L, Suls A et al (2009) The SCN1A variant database: a novel research and diagnostic tool. Hum Mutat 30:E904-E920

15. Dichigans M, Freilinger T, Eckstein G et al (2005) Mutation in the neuronal voltage-gated sodium channel SCN1A in familial hemiplegic migraine. Lancet 66:317-377

16. Headache Classification Subcommittee of the International Headache Society (2004) The International Classification of Headache Disorders: 2nd edn. Cephalalgia (suppl 1):9-160

17. Herrman MG, Durtschi JD, Bromley KL et al (2006) Amplicon DNA melting analysis for mutation scanning and genotyping: cross-platform comparison of instruments and dyes. Clin Chem 52:494-503

18. Liew M, Pryor R, Palais R et al (2004) Genotyping of singlenucleotide polymorphisms by high-resolution melting of small amplicons. Clin Chem 50:1156-1164 
19. Reed GH, Kent JO, Wittwer CT (2007) High-resolution DNA melting analysis for simple and efficient molecular diagnostics. Pharmacogenomics 8:597-608

20. Chioza B, Wilkie H, Nashef L et al (2001) Association between the alpha (1a) calcium channel gene CACNA1A and idiopathic generalized epilepsy. Neurology 56:1245-1246

21. Jouvenceau A, Eunson LH, Spauschus A et al (2001) Human epilepsy associated with dysfunction of the brain P/Q-type calcium channel. Lancet 358:801-807

22. Chioza B, Nashef L, Asherson P et al (2002) CACNA1A and $\mathrm{P} / \mathrm{Q}$-type calcium channels in epilepsy. Lancet 359:258

23. Deprez L, Peeters K, Van Paesschen WV et al (2007) Familial occipitaltemporal lobe epilepsy and migraine with visual aura: linkage to chromosome 9 . Neurology 68:1-8

24. Ohmori I, Ouchida M, Ohtsuka Y et al (2002) Significant correlation of the SCN1A mutations and severe myoclonic epilepsy in infancy. Biochem Biophys Res Commun 295:17-23

25. Nabbout R, Kozlovski A, Gennaro E et al (2003) Absence of mutations in major GEFS+ genes in myoclonic astatic epilepsy. Epilepsy Res 56:127-133

26. Depienne C, Trouillard O, Saint-Martin C et al (2009) Spectrum of SCN1A gene mutations associated with Dravet syndrome: analysis of 333 patients. J Med Genet 46:183-191

27. Wallace RH, Scheffer IE, Barnett S et al (2001) Neuronal sodium-channel alpha1-subunit mutations in generalized epilepsy with febrile seizures plus. Am J Hum Genet 68:859-865

28. Bonanni P, Malcarne M, Moro F et al (2004) Generalized epilepsy with febrile seizures plus (GEFS+): clinical spectrum in seven Italian families unrelated to SCN1A, SCN1B, and GABRG2 gene mutations. Epilepsia 45:149-158

29. Malacarne M, Madia F, Gennaro E et al (2002) Lack of SCN1A mutations in familial febrile seizures. Epilepsia 43:559-562

30. Chou IC, Peng CT, Tsai FJ et al (2003) The lack of association between febrile convulsions and polymorphisms in SCN1A. Epilepsy Res 54:53-57

31. von Brevern M, Ta N, Shankar A et al (2006) Migrainous vertigo: mutation analysis of the candidate genes CACNA1A, ATP1A2, SCN1A, and CACNB4. Headache 46:1136-1141
32. Kwan P, Poon WS, Ng HK et al (2008) Multidrug resistance in epilepsy and polymorphisms in the voltage-gated sodium channel genes SCN1A, SCN2A, and SCN3A: correlation among phenotype, genotype, and mRNA expression. Pharmacogenet Genomics 18:989-998

33. Lakhan R, Kumari R, Misra UK et al (2009) Differential role of sodium channels SCN1A and SCN2A gene polymorphisms with epilepsy and multiple drug resistance in the north Indian population. Br J Clin Pharmacol 68:214-220

34. Escayg A, Heils A, MacDonald BT et al (2001) A novel SCN1A mutation associated with generalized epilepsy with febrile seizures plus and prevalence of variants in patients with epilepsy. Am J Hum Genet 68:866-873

35. Harkin LA, McMahon JM, Iona X et al (2007) The spectrum of SCN1A-related infantile epileptic encephalopathies. Brain 130:843-852

36. Depienne C, Trouillard O, Saint-Martin C et al (2009) Spectrum of SCN1A gene mutations associated with Dravet syndrome: analysis of 333 patients. J Med Genet 46:183-191

37. Smith RD, Goldin AL (1997) Phosphorylation at a single site in the rat brain sodium channel is necessary and sufficient for current reduction by protein kinase A. J Neurosci 17:6086-6093

38. Vankmolkot KR, Kors EE, Hottenga JJ et al (2003) Novel mutations in the Na, K-ATPase pump gene ATP1A2 associated with familial hemiplegic migraine and benign familial infantile convulsions. Ann Neurol 54:360-366

39. Montagna P (2008) Migraine: a genetic disease? Neurol Sci 29(S1):47-51

40. Grosso S, Orrico A, Galli L et al (2007) SCN1A mutation associated with atypical Panayiotopoulos syndrome. Neurology 69:609-611

41. Weiss LA, Escayg A, Kearney JA et al (2003) Sodium channels SCN1A, SCN2A and SCN3A in familial autism. Mol Psychiatry 8:186-194 